\title{
Absence of an interaction between the angiotensin- converting enzyme insertion-deletion polymorphism and pravastatin on cardiovascular disease in high-risk hypertensive patients: The Genetics of Hypertension-Associated Treatment (GenHAT) study
}

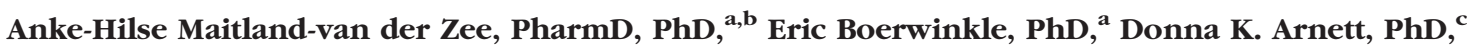
Barry R. Davis, MD, PhD, ${ }^{\text {a }}$ Catherine Leiendecker-Foster, $M S,{ }^{\text {d }}$ Michael B. Miller, PhD, ${ }^{\mathrm{c}}$ Olaf H. Klungel, PharmD, PhD, ${ }^{\mathrm{c}}$ Charles E. Ford, PhD, ${ }^{\mathrm{a}}$ and John H. Eckfeldt, MD, PhD ${ }^{\mathrm{d}}$ Houston, TX; Utrecht, The Netherlands; Birmingham, AL; and Minneapolis, $M N$

Background The aim of this study was to determine whether the angiotensin-converting enzyme (ACE) insertiondeletion (ID) polymorphism interacts with pravastatin to modify the risk of coronary heart disease (CHD) and other cardiovascular end points in a large clinical trial.

Methods GenHAT is an ancillary study of the ALLHAT. The ACE ID genotyped population in the lipid-lowering arm of ALLHAT included 9467 participants randomly assigned to pravastatin $(n=4741)$ or to usual care $(n=4726)$. The efficacy of pravastatin in reducing the risk of primary outcome (all-cause mortality) and secondary outcomes (fatal CHD and nonfatal myocardial infarction, cardiovascular disease [CVD] mortality, CHD, stroke, other CVD, non-CVD mortality, stroke, and heart failure) was compared between the genotype strata (dominant model ID + II vs DD, additive model II vs ID vs DD), by examining an interaction term in a Cox proportional hazards model.

Results The relative risk of fatal CHD and nonfatal myocardial infarction among subjects randomized to pravastatin compared with subjects randomized to usual care was similar in subjects with the II genotype (hazard ratio [HR] 0.84, 95\% $\mathrm{Cl}$ 0.59-1.18), the ID genotype (HR 0.84, 95\% Cl 0.68-1.03), and the DD genotype (HR 0.99, 95\% Cl 0.77-1.27).

Conclusions We found no evidence that the ACE ID genotype was a major modifier of the efficacy of pravastatin in reducing the risk of cardiovascular events. (Am Heart J 2007;153:54-8.)

The efficacy of cholesterol-lowering drug therapy in primary and secondary prevention has been firmly established. The combined results of 9 large long-term statin trials (including the ALLHAT-LLT) showed a $27 \%$ reduction in coronary heart disease (CHD) events and a $14 \%$ reduction in all-cause mortality. ${ }^{1-9}$ These reductions,

From the ${ }^{a}$ School of Public Health, University of Texas Health Science Center at Houston, 1200 Hermann Pressler, Houston TX, b Division of Pharmacoepidemiology \& Pharmacotherapy, Utrecht Institute of Pharmaceutical Sciences, Utrecht University, Utrecht, The Netherlands, "University of Alabama at Birmingham, Birmingham, AL and d'Department of Laboratory Medicine and Pathology, University of Minnesota, Minneapolis, MN.

Submitted March 30, 2006; accepted October 23, 2006.

Reprint requests: Anke-Hilse Maitland-van der Zee, PharmD, PhD, Utrecht University, Faculty of Science, Utrecht Institute for Pharmaceutical Sciences, Division of Pharmacoepidemiology and Pharmacotherapy, Sorbonnelaan 16, PO Box 80082, 3508 TB Utrecht, The Netherlands.

E-mail: a.h.maitland@pharm.uu.nl

0002-8703/\$ - see front matter

(C) 2007, Mosby, Inc. All rights reserved.

doi:10.1016/i.ahj.2006.10.019 however, were average effects of statin therapy for all patients included in the trials. Pharmacogenetic findings suggest that patients may differ in their response to statins because of their genetic constitution. ${ }^{10}$

The angiotensin-converting enzyme (ACE) is thought to play an important role in the development of coronary artery disease. Plasma and cellular levels of ACE are associated with a large insertion-deletion (ID) polymorphism located in intron 16 of the ACE gene. DD carriers have about twice the plasma levels of ACE compared with II carriers, whereas heterozygotes have intermediate levels. ${ }^{11}$ In a meta-analysis including 145 reports with an overall sample size of 49959, the excess risk in subjects with the DD genotype compared with subjects with the II genotype was $32 \%$ for coronary heart disease (30 studies) and $45 \%$ for myocardial infarction (MI) (20 studies). ${ }^{12}$

Contradictory results have been published on the influence of the ACE ID polymorphism on the effec- 
Table I. Baseline characteristics of the pravastatin and usual care subgroups, according to ACE ID genotype

\begin{tabular}{|c|c|c|c|c|c|c|}
\hline \multirow[b]{3}{*}{ Characteristic } & \multicolumn{6}{|c|}{ ACE genotype } \\
\hline & \multicolumn{2}{|c|}{ II } & \multicolumn{2}{|c|}{ ID } & \multicolumn{2}{|c|}{ DD } \\
\hline & Pravastatin & Usual care & Pravastatin & Usual care & Pravastatin & Usual care \\
\hline Sample size & $951(20.1)$ & $922(19.5)$ & $2376(50.1)$ & $2336(49.4)$ & $1414(29.8)$ & $1468(31.1)$ \\
\hline Age $(y)$ & $65.95(7.5)$ & $66.13(7.8)$ & $66.64(7.7)$ & $66.17(7.4)$ & $66.32(7.8)$ & $66.34(7.6)$ \\
\hline \multicolumn{7}{|l|}{ Race } \\
\hline White & $551(57.9)$ & $567(61.5)$ & $1358(57.2)$ & $1367(58.5)$ & $778(55.1)$ & $806(54.9)$ \\
\hline Black & $304(32.0)$ & $274(29.7)$ & $897(37.8)$ & $824(35.3)$ & $572(40.4)$ & $587(40.0)$ \\
\hline Other & $96(10.1)$ & $81(8.8)$ & $121(5.0)$ & $145(6.2)$ & $64(4.5)$ & $75(5.1)$ \\
\hline Sex (male) & $481(50.6)$ & $471(51.1)$ & 1218 (51.3) & $1185(50.7)$ & $735(52.0)$ & $747(50.9)$ \\
\hline Lipid medications in the last year & $14(1.5)$ & $19(2.1)$ & $38(1.6)$ & $33(1.4)$ & 27 (1.9) & $20(1.4)$ \\
\hline $\mathrm{SBP}(\mathrm{mm} \mathrm{Hg})$ & $145(13.9)$ & $146(14.2)$ & $145(14.1)$ & 145 (13.9) & 145 (13.7) & $145(14.1)$ \\
\hline $\mathrm{DBP}(\mathrm{mm} \mathrm{Hg})$ & $84(9.7)$ & $84(9.9)$ & $84(10.0)$ & $84(9.7)$ & $84(9.6)$ & $84(10.0)$ \\
\hline Smoker & $211(22.2)$ & $245(26.6)$ & $548(23.1)$ & $525(22.5)$ & $353(25.0)$ & $339(23.1)$ \\
\hline History of diabetes & $359(37.8)$ & $286(31.0)$ & $843(35.5)$ & $834(35.7)$ & 477 (33.7) & $501(34.1)$ \\
\hline History of Ml or stroke & $164(17.3)$ & 145 (15.7) & $397(16.7)$ & 408 (17.5) & 248 (17.5) & $268(18.3)$ \\
\hline History of CHD & $131(13.8)$ & $146(15.8)$ & $333(14.0)$ & 344 (14.7) & $178(12.6)$ & $227(15.5)$ \\
\hline BMI & $30.1(6.0)$ & $29.7(6.2)$ & $29.8(5.9)$ & $29.9(6.1)$ & $29.8(5.9)$ & $30.2(6.2)$ \\
\hline Total cholesterol & $224.7(26.2)$ & 223.1 (26.3) & $223.2(27.3)$ & $223.5(26.3)$ & 223.5 (26.9) & $223.9(26.6)$ \\
\hline HDL cholesterol & $47.0(13.6)$ & $46.9(13.5)$ & $47.6(13.4)$ & $47.2(13.2)$ & $47.9(13.3)$ & $47.7(13.9)$ \\
\hline LDL cholesterol & $145.5(20.5)$ & 144.9 (20.9) & $145.2(21.9)$ & $145.3(21.4)$ & $145.8(21.1)$ & $145.5(21.3)$ \\
\hline \multicolumn{7}{|l|}{ Antihypertensive treatment group } \\
\hline Doxazosin & $180(18.9)$ & $194(21.0)$ & $497(20.9)$ & $508(21.8)$ & $316(22.3)$ & $309(21.1)$ \\
\hline Chlorthalidone & $367(38.9)$ & $348(37.7)$ & $838(35.3)$ & $850(36.4)$ & $513(36.3)$ & $516(35.2)$ \\
\hline Amlodipine & $196(20.6)$ & 197 (21.4) & $536(22.6)$ & $501(21.5)$ & $292(20.7)$ & $315(21.5)$ \\
\hline Lisinopril & 208 (21.9) & 183 (19.9) & $505(21.3)$ & $477(20.4)$ & $293(20.7$ & $328(22.3)$ \\
\hline
\end{tabular}

$B M I$, Body mass index; HDL, high-density lipoprotein; LDL, low-density lipoprotein.

tiveness of statins. In the CARE trial, no effect was found for the ACE ID polymorphism alone on the efficacy of pravastatin in reducing the primary end point. ${ }^{13}$ In the LCAS study, subjects with the ACE DD genotype had the strongest reduction of coronary atherosclerosis with pravastatin. However, the distribution of clinical events among genotypes was not significantly different. ${ }^{14}$ In an observational cohort study among subjects with hypercholesterolemia the beneficial effect of statins on coronary heart disease was different for men with different ACE genotypes. In men with 2 I alleles, the largest beneficial effects of statins were demonstrated, whereas in men with $2 \mathrm{D}$ alleles, no beneficial effects were demonstrated. ${ }^{15}$ The objective of this study was to determine whether the ACE ID polymorphism interacts with pravastatin to modify the risk of CHD and other cardiovascular end points in a large randomized clinical trial of high-risk individuals.

\section{Methods}

\section{Study Population and Design}

GenHAT is an ancillary study of the ALLHAT. The LLT component of ALLHAT was designed to evaluate the impact of large sustained cholesterol reductions on all-cause mortality in a hypertensive cohort with at least 1 other CHD risk factor and to assess CHD reduction and other benefits in populations that had been excluded or underrepresented in previous trials, particularly older persons, women, racial and ethnic minority groups, and persons with diabetes. A priori secondary outcomes included a combination of CHD death (fatal CHD, coronary revascularization-related mortality, previous angina or MI and no known potentially lethal noncoronary disease process) and nonfatal MI, cardiovascular disease (CVD) mortality (mortality due to $\mathrm{CHD}$, stroke, other treated angina, heart failure, peripheral disease), CHD (CHD death, coronary revascularization, hospitalized angina), fatal stroke, other CVD, non-CVD mortality, stroke (fatal and nonfatal), and heart failure. The design of ALLHAT, including the LLT, and its participant and clinical site recruitment and selection have been reported elsewhere. ${ }^{9,16-18}$ Briefly, ALLHAT-LLT was a randomized, nonblinded, large simple trial conducted from February 1994 through March 2002 at 513 clinical centers in the United States, Puerto Rico, US Virgin Islands, and Canada. The intervention was open-label pravastatin $(40 \mathrm{mg} / \mathrm{d})$ versus usual care. Participants were drawn exclusively from the ALLHAT antihypertensive trial. The protocol of ALLHAT was approved by each participating center's institutional review board. The GenHAT study was approved by the institutional review boards of the University of Minnesota and the University of Texas Health Science Center at Houston.

\section{Statistical methods}

Participants were stratified according to genotype, and baseline characteristics were compared using $\chi^{2}$ and $t$ tests. The efficacy of pravastatin in reducing the risk of the primary 
Table II. Total number of trial events and cumulative 6-year Kaplan-Meier risk estimates of clinical outcomes by ACE genotype and lipid treatment group

ACE ID genotype

\begin{tabular}{|c|c|c|c|c|c|c|c|c|}
\hline \multirow[b]{3}{*}{ Trial outcome } & \multirow{2}{*}{\multicolumn{2}{|c|}{ All }} & \multirow{2}{*}{\multicolumn{2}{|c|}{ II }} & \multirow{2}{*}{\multicolumn{2}{|c|}{ ID }} & & \\
\hline & & & & & & & \multicolumn{2}{|c|}{ DD } \\
\hline & Prav & UC & Prav & UC & Prav & UC & Prav & UC \\
\hline Sample size & 4741 & 4726 & 951 & 922 & 2376 & 2336 & 1414 & 1468 \\
\hline All-cause mortality & $\begin{array}{l}584 \\
0.1441\end{array}$ & $\begin{array}{l}566 \\
0.1402\end{array}$ & $\begin{array}{l}101 \\
0.1328\end{array}$ & $\begin{array}{l}108 \\
0.1409\end{array}$ & $\begin{array}{l}302 \\
0.1482\end{array}$ & $\begin{array}{l}286 \\
0.1460\end{array}$ & $\begin{array}{l}181 \\
0.1462\end{array}$ & $\begin{array}{l}172 \\
0.1363\end{array}$ \\
\hline CVD deaths & $\begin{array}{l}273 \\
0.0685\end{array}$ & $\begin{array}{l}272 \\
0.0670\end{array}$ & $\begin{array}{l}45 \\
0.0570\end{array}$ & $\begin{array}{l}55 \\
0.0666\end{array}$ & $\begin{array}{l}145 \\
0.0732\end{array}$ & $\begin{array}{l}139 \\
0.0704\end{array}$ & $\begin{array}{l}83 \\
0.0686\end{array}$ & $\begin{array}{l}78 \\
0.0617\end{array}$ \\
\hline $\mathrm{CHD}$ & $\begin{array}{l}149 \\
0.0371\end{array}$ & $\begin{array}{l}150 \\
0.0372\end{array}$ & $\begin{array}{l}24 \\
0.0309\end{array}$ & $\begin{array}{l}27 \\
0.0314\end{array}$ & $\begin{array}{l}82 \\
0.0397\end{array}$ & $\begin{array}{l}78 \\
0.0399\end{array}$ & $\begin{array}{l}43 \\
0.0377\end{array}$ & $\begin{array}{l}45 \\
0.0356\end{array}$ \\
\hline Stroke & $\begin{array}{l}48 \\
0.0120\end{array}$ & $\begin{array}{l}49 \\
0.0127\end{array}$ & $\begin{array}{l}9 \\
0.0125\end{array}$ & $\begin{array}{l}15 \\
0.0219\end{array}$ & $\begin{array}{l}19 \\
0.0088\end{array}$ & $\begin{array}{l}17 \\
0.0088\end{array}$ & $\begin{array}{l}20 \\
0.0173\end{array}$ & $\begin{array}{l}17 \\
0.0139\end{array}$ \\
\hline Other CVD & $\begin{array}{l}76 \\
0.0208\end{array}$ & $\begin{array}{l}73 \\
0.0184\end{array}$ & $\begin{array}{l}12 \\
0.0145\end{array}$ & $\begin{array}{l}13 \\
0.0149\end{array}$ & $\begin{array}{l}44 \\
0.0263\end{array}$ & $\begin{array}{l}44 \\
0.0232\end{array}$ & $\begin{array}{l}20 \\
0.0151\end{array}$ & $\begin{array}{l}16 \\
0.0134\end{array}$ \\
\hline Non-CVD mortality & $\begin{array}{l}277 \\
0.0711\end{array}$ & $\begin{array}{l}259 \\
0.0694\end{array}$ & $\begin{array}{l}50 \\
0.0684\end{array}$ & $\begin{array}{l}46 \\
0.0693\end{array}$ & $\begin{array}{l}141 \\
0.0719\end{array}$ & $\begin{array}{l}131 \\
0.0709\end{array}$ & $\begin{array}{l}86 \\
0.0720\end{array}$ & $\begin{array}{l}82 \\
0.0719\end{array}$ \\
\hline Fatal CHD and nonfatal MI & $\begin{array}{l}349 \\
0.0904\end{array}$ & $\begin{array}{l}392 \\
0.1031\end{array}$ & $\begin{array}{l}61 \\
0.0830\end{array}$ & $\begin{array}{l}70 \\
0.0921\end{array}$ & $\begin{array}{l}172 \\
0.0864\end{array}$ & $\begin{array}{l}198 \\
0.1063\end{array}$ & $\begin{array}{l}116 \\
0.1032\end{array}$ & $\begin{array}{l}124 \\
0.1032\end{array}$ \\
\hline Fatal and nonfatal stroke & $\begin{array}{l}192 \\
0.0552\end{array}$ & $\begin{array}{l}212 \\
0.0510\end{array}$ & $\begin{array}{l}38 \\
0.0537\end{array}$ & $\begin{array}{l}50 \\
0.0727\end{array}$ & $\begin{array}{l}84 \\
0.0469\end{array}$ & $\begin{array}{l}90 \\
0.0449\end{array}$ & $\begin{array}{l}70 \\
0.0593\end{array}$ & $\begin{array}{l}72 \\
0.0615\end{array}$ \\
\hline Heart failure (hospitalized or fatal) & $\begin{array}{l}229 \\
0.0604\end{array}$ & $\begin{array}{l}232 \\
0.0616\end{array}$ & $\begin{array}{l}40 \\
0.0541\end{array}$ & $\begin{array}{l}50 \\
0.0650\end{array}$ & $\begin{array}{l}128 \\
0.0677\end{array}$ & $\begin{array}{l}107 \\
0.0555\end{array}$ & $\begin{array}{l}61 \\
0.0505\end{array}$ & $\begin{array}{l}75 \\
0.0678\end{array}$ \\
\hline
\end{tabular}

Prav, Pravastatin; UC, usual care.

Table III. Unadjusted and adjusted and $95 \% \mathrm{Cls}$ of the ID and DD genotypes relative to the II genotype for combined randomized groups

ID

\begin{tabular}{|c|c|c|c|c|c|}
\hline & \multirow[b]{2}{*}{ II reference } & & \\
\hline & & $\begin{array}{c}\text { Unadjusted HR } \\
(95 \% \mathrm{CI})\end{array}$ & $\begin{array}{l}\text { Adjusted HR* } \\
(95 \% \mathrm{Cl})\end{array}$ & $\begin{array}{c}\text { Unadjusted HR } \\
(95 \% \mathrm{CI})\end{array}$ & $\begin{array}{c}\text { Adjusted HR* } \\
(95 \% \mathrm{Cl})\end{array}$ \\
\hline All-cause mortality & 1 & $1.12(0.96-1.31)$ & $1.11(0.94-1.29)$ & $1.09(0.91-1.29)$ & $1.08(0.91-1.29)$ \\
\hline CVD mortality & 1 & $1.13(0.90-1.42)$ & $1.12(0.89-1.41)$ & $1.04(0.81-1.33)$ & $1.03(0.80-1.33)$ \\
\hline CHD & 1 & $1.25(0.91-1.71)$ & $1.25(0.91-1.71)$ & $1.11(0.79-1.57)$ & $1.10(0.78-1.56)$ \\
\hline Stroke & 1 & $0.59(0.35-1.00)$ & $0.59+(0.35-0.99)$ & $1.00(0.60-1.67)$ & $0.96(0.57-1.61)$ \\
\hline Other CVD & 1 & $1.40(0.90-2.19)$ & $1.36(0.87-2.13)$ & $0.93(0.56-1.56)$ & $0.95(0.57-1.58)$ \\
\hline Non-CVD mortality & 1 & $1.13(0.89-1.42)$ & $1.11(0.88-1.40)$ & $1.13(0.88-1.45)$ & $1.14(0.88-1.46)$ \\
\hline Fatal CHD and nonfatal MI & 1 & $1.13(0.92-1.38)$ & $1.14(0.93-1.39)$ & 1.19 (0.96-1.48) & $1.20(0.97-1.49)$ \\
\hline Stroke (fatal and nonfatal) & 1 & $0.78(0.61-1.01)$ & $0.76 \ddagger(0.59-0.98)$ & $1.04(0.80-1.36)$ & $1.00(0.76-1.31)$ \\
\hline Heart Failure (hospitalized or fatal) & 1 & $1.04(0.81-1.32)$ & $1.03(0.81-1.31)$ & $0.98(0.75-1.27)$ & $0.98(0.75-1.28)$ \\
\hline
\end{tabular}

*Adjusted for treatment group (pravastatin/usual care), sex (male/female), race (black/white), and 8 baseline variables: current smoking status (yes/no), history of diabetes (yes/ no), history of $\mathrm{CHD}$ (yes/no), systolic blood pressure level $(\mathrm{mm} \mathrm{Hg})$, and age (years).

$\dagger P=.047$.

$\ddagger P=.038$.

outcome (all-cause mortality) and of a priori secondary outcomes is compared between the genotype strata (II + ID vs DD), using an interaction term in the Cox proportional hazards model. These analyses were adjusted for the following potential confounding baseline factors: sex (men/women), race (black/white), current smoking status (yes/no), history of diabetes (yes/no), history of CHD (yes/no), visit 1 systolic blood pressure ( $\mathrm{mm} \mathrm{Hg}$ ), and age (years). Because of our previous finding that the interaction between the ACE ID polymorphism and effectiveness of statins may be modified by sex, ${ }^{19}$ a 3-way interaction for sex-ACE genotype-statin therapy was included in the model to compare the interaction between men and women. We also included a 3-way interaction for race-ACE genotype-statin therapy in the model to examine whether ethnicity accounted for differences in the pharmacogenetic effect of the ACE ID genotype on the primary and secondary outcomes.

\section{Results}

The genotyped population in the lipid-lowering arm of ALLHAT included 9467 participants. Of these, 4741 
Table IV. Adjusted HRs and $95 \% \mathrm{Cls}$ of the effect of pravastatin versus usual care on study outcomes, according to II, ID, and DD genotype strata

\begin{tabular}{|c|c|c|c|c|c|}
\hline & HR $_{\text {adi }}(95 \% \mathrm{Cl})$ & HR $_{\text {adi }}(95 \% \mathrm{Cl})$ & $\mathbf{H R}_{\mathrm{adj}}(\mathbf{9 5} \% \mathrm{Cl})$ & IHR $_{\text {adj }}(95 \% \mathrm{Cl})^{*}$ & IHR $_{\text {adj }}(95 \% \mathrm{CI})^{*}$ \\
\hline Trial outcome & II & ID & DD & II versus DD & ID versus DD \\
\hline All-cause mortality & $0(0.68-1.18)$ & 0.99 (0.84-1. & 1.0910 .89 & 0.8110 & 0.901 \\
\hline CVD mortality & $0.79(0.53-1.18)$ & $0.98(0.78-1.24)$ & $1.10(0.81-1.50)$ & $0.70(0.42-1.15), 0.16$ & $0.87(0.59-1.29), 0.49$ \\
\hline $\mathrm{CHD}$ & $0.84(0.48-1.46)$ & $1.00(0.73-1.37)$ & $1.01(0.66-1.53)$ & $0.82(0.41-1.64), 0.58$ & $0.98(0.58-1.65), 0.94$ \\
\hline Fatal stroke & $0.60(0.26-1.39)$ & $1.02(0.53-1.97)$ & $1.22(0.64-2.33)$ & $0.47(0.16-1.34), 0.16$ & $0.83(0.33-2.10), 0.70$ \\
\hline Other CVD & $0.93(0.42-2.05)$ & $0.91(0.60-1.39)$ & $1.22(0.63-2.36)$ & $0.71(0.26-1.99), 0.52$ & $0.71(0.33-1.55), 0.39$ \\
\hline Non-CVD mortality & $1.04(0.69-1.55)$ & $1.00(0.79-1.27)$ & $1.09(0.81-1.48)$ & $0.95(0.58-1.57), 0.85$ & $0.92(0.63-1.35), 0.67$ \\
\hline Fatal $\mathrm{CHD}$ and nonfatal $\mathrm{MI}$ & $0.84(0.59-1.18)$ & $0.84(0.68-1.03)$ & $0.99(0.77-1.27)$ & $0.84(0.55-1.29), 0.43$ & $0.85(0.61-1.17), 0.31$ \\
\hline Stroke (fatal and nonfatal) & $0.73(0.48-1.11)$ & $0.88(0.66-1.19)$ & $1.03(0.74-1.43)$ & $0.69(0.41-1.19), 0.18$ & $0.86(0.55-1.35), 0.52$ \\
\hline Heart failure (hospitalized or fatal) & $0.75(0.50-1.14)$ & $1.15(0.89-1.48)$ & $0.85(0.61-1.20)$ & $0.87(0.51-1.49) \quad 0.61$ & $1.32(0.86-2.02), 0.20$ \\
\hline
\end{tabular}

Adjusted for differences in sex (male/female), race (black/white), and 5 baseline variables: current smoking status (yes/no), history of diabetes (yes/no), history of CHD (yes/no), systolic blood pressure level $(\mathrm{mm} \mathrm{Hg})$, age (years). The adjusted IHRs ${ }^{a}$ of the II versus the DD genotype and the ID versus the DD genotype are given. The IHR estimates for a given outcome were obtained from respective Cox proportional hazards models incorporating treatment, genotype (II/DD and ID/DD), treatment by genotype interactions, and 7 baseline covariates. IHR adj, Adjusted IHR.

${ }^{a}$ The interaction hazard ratio is a ratio of ratios: Prav/UC for II stratum over Prav/UC for DD stratum, and similarly for ID versus DD.

*P Test of null hypothesis: adjusted IHR 1.0.

were in the pravastatin treatment group and 4726 were in the usual care group. In Table I, baseline characteristics according to ACE ID genotype for subjects randomized to pravastatin and subjects in the usual care group are shown.

The proportions and characteristics within each of the 3 genotypes assigned to each treatment (pravastatin vs usual care) were well balanced.

The total number of trial events and the cumulative 6-year Kaplan-Meier event rates of clinical outcomes by ACE genotype and treatment are shown in Table II. The effects of ACE ID on the clinical outcomes (regardless of pravastatin treatment assignment) can be found in Table III. Subjects with the ID genotype had a statistically significant lower risk of fatal and nonfatal stroke compared with subjects with the II genotype (adjusted hazard ratio [HR $\mathrm{Hdj}]$ 0.76, 95\% CI 0.59-0.99). This finding was marginally significant for fatal strokes alone $(P=.051)$.

Hazard ratios of the effect of statin use are shown, by genotype, in Table IV. Three-way analyses of the ACE ID genotypes, treatment, and primary clinical outcome (all-cause mortality) identified no differences in the efficacy of pravastatin between subjects with the II and DD genotypes (interaction HR [IHR] 0.81, 95\% CI $0.58-1.14, P=.31$ ), or between subjects with the ID and DD genotypes (IHR 0.90, 95\% CI 0.69-1.17, $P=.42$ ) (Table IV). The secondary end points were consistent with these negative findings. No significant gene-drug interactions were found. We evaluated gene-drug interactions in relation to the primary and secondary outcomes in subgroups based on sex and on race. There were no apparent gene-treatment interactions across sex-gene-drug or race-gene-drug subgroups (data not shown).

\section{Discussion}

The GenHAT-LLT study is a large pharmacogenetic trial of pravastatin versus usual care. Based on genotype data collected from almost 10000 individuals, who were followed for cardiovascular events using standard, well-defined definitions for cardiovascular outcomes, we found no compelling evidence that ACE ID genotype is a major determinant of the efficacy of pravastatin in reducing the risk of cardiovascular events. We did not find any significant interactions in the response to therapy, despite the large number of tests performed. We did observe that participants with the II and ID genotypes tended to fare better on pravastatin than usual care for most of the outcomes examined, whereas the opposite was true for the DD participants. The II versus DD and the ID versus DD interaction hazard ratios were $<1.00$ for all outcomes except heart failure, ranging from 0.47 for fatal strokes (II vs DD) to 0.98 for CHD (ID vs DD). This is in concordance with what would be expected based on a previous study. ${ }^{15}$

The GenHAT study selected individuals based on preexisting coronary risk factors and hypertension. Therefore, there is some uncertainty about the applicability of the findings of this study to the association in subjects without these risk factors.

In the ALLHAT study, no overall beneficial effect of pravastatin was demonstrated on the primary outcome. After 6 years of follow-up, 26\% of subjects in the usual care arm used statins, and $16 \%$ in the pravastatin arm did not use a lipid-lowering drug anymore. There was no significant differential in crossovers among ACE genotypes and therefore would not affect the interaction between pravastatin and the ACE polymorphism. 
Our finding that the ACE ID polymorphism did not modify the efficacy of statins was in concordance with 3 studies. ${ }^{13,14,19}$ Results were different from the results of the Rotterdam study that found a significant interaction in men. ${ }^{15}$ Although no statistically significant interaction was found in GenHAT, there was a trend toward better efficacy in the subjects with the II and ID genotypes compared with the DD genotype. For example, subjects with the ID genotype tended to fare better on pravastatin than usual care for fatal CHD and nonfatal MI ( $\mathrm{HR}_{\text {adj }} 0.84,95 \%$ CI 0.68-1.03), whereas there was no effect of pravastatin in subjects with the DD genotype $\left(\mathrm{HR}_{\mathrm{adj}} 0.99,95 \% \mathrm{CI} 0.77-1.27\right)$. This result is similar to the findings in the Rotterdam study. However, we did not find evidence that there were differences in efficacy between men and women as was found in the Rotterdam Study. The physiological role of the renin-angiotensin system varies with sodium intake, age, and disease status. ${ }^{20}$ Because this trial included high-risk hypertensive patients, while the Rotterdam cohort study included a hypercholesterolemic subset of the general population, this might be an explanation for the different findings in men. A strength of the GenHAT study, however, is that it was performed in a large clinical trial with reasonable event rates in both subjects randomized to pravastatin and in subjects randomized to usual care. Furthermore, because only the ID polymorphism was studied, an effect of other polymorphisms in the ACE gene on pravastatin cannot be ruled out.

These pharmacogenetic analyses of the ALLHAT-LLT in combination with results from earlier studies provide no rationale for using ACE ID genotype to guide decisions about treatment with pravastatin. Because there was a trend toward less efficacy in subjects with the DD genotype, more research in larger settings, possibly combinations of different trials/cohort studies, is necessary.

\section{References}

1. Anonymous. Randomised trial of cholesterol lowering in 4444 patients with coronary heart disease: the Scandinavian Simvastatin Survival Study. Lancet 1994;344:1383-9.

2. Shepherd J, Cobbe SM, Ford I, et al. Prevention of coronary heart disease with pravastatin in men with hypercholesterolemia. N Engl J Med 1995;333:1301-7.

3. Sacks F, Pfeffer MA, Moye LA, et al. The effect of pravastatin on coronary events after myocardial infarction in patients with average cholesterol levels. N Engl J Med 1996;335:1001-9.

4. Anonymous. Prevention of cardiovascular events and death with pravastatin in patients with coronary heart disease and a broad range of initial cholesterol levels. N Engl J Med 1998;339:1349- 57.

5. Downs JR, Clearfield M, Weis S, et al. Primary prevention of acute coronary events with lovastatin in men and women with average cholesterol levels. Results of AFCAPS/TexCAPS. JAMA 1998;279:1615-22.

6. Anonymous. MRC/BHF Heart protection study of cholesterol lowering with simvastatin in 20,536 high risk individuals; a randomized placebo controlled trial. Lancet 2002;360:7-22.

7. The Post Coronary Artery Bypass Graft Trial Investigators. The effect of aggressive lowering of low-density lipoprotein cholesterol levels and low-dose anticoagulation on obstructive changes in saphenous-vein coronary-artery bypass grafts. N Engl J Med 1997;336:153- 62.

8. Serruys PW, deFeyter P, Macaya C, et al. Fluvastatin for prevention of cardiac events following successful first percutaneous coronary intervention: a randomized controlled trial. JAMA 2002;287:3215- 22.

9. Major outcomes in moderately hypercholesterolemic, hypertensive patients randomized to pravastatin vs usual care: The Antihypertensive and Lipid-Lowering Treatment to Prevent Heart Attack Trial (ALLHAT-LLT). JAMA 2002;288:2998-3007.

10. Maitl-van der Zee AH, Klungel OH, Stricker BHCh, et al. Genetic polymorphisms: importance for response to HMG-CoA reductase inhibitors. Atherosclerosis 2002;163:213-22.

11. Rigat $B$, Hubert $C$, Alhenc-Gelas $F$, et al. An insertion/deletion polymorphism in the angiotensin I-converting enzyme gene accounting for half the variance of serum enzyme levels. J Clin Invest 1990;86:1343- 6.

12. Staessen JA, Wang JG, Ginocchio G, et al. The deletion/insertion polymorphism of the angiotensin converting enzyme gene and cardiovascular-renal risk. J Hypertens 1997;15:1579-92.

13. Bray PF, Cannon CP, Goldschmidt-Clermont $P$, et al. The platelet $P I(A 2)$ and angiotensin-converting enzyme (ACE) D allele polymorphisms and the risk of recurrent events after acute myocardial infarction. Am J Cardiol 2001;88:347-52.

14. Marian AJ, Safavi F, Ferlic L, et al. Interactions between angiotensin-I converting enzyme insertion/deletion polymorphism and response of plasma lipids and coronary atherosclerosis to treatment with fluvastatin: the lipoprotein and coronary atherosclerosis study. J Am Coll Cardiol 2000;35:89-95.

15. Maitl-van der Zee $\mathrm{AH}$, Stricker $\mathrm{BH}$, Klungel $\mathrm{OH}$, et al. Effectiveness of HMG-CoA reductase inhibitors is modified by the ACE insertion deletion polymorphism. Atherosclerosis 2004; 175:377-9.

16. Davis BR, Cutler JA, Gordon DJ, et al. Rationale and design for the Antihypertensive and Lipid Lowering Treatment to Prevent Heart Attack Trial (ALLHAT), ALLHAT Research Group. Am J Hypertens 1996;9:342-60.

17. Pressel S, Davis BR, Louis GT, et al. Participant recruitment in the Antihypertensive and Lipid-Lowering Treatment to Prevent Heart Attack Trial (ALLHAT). Control Clin Trials 2001;22:674-86.

18. Wright Jr JT, Cushman WC, Davis BR, et al. The Antihypertensive and Lipid-Lowering Treatment to Prevent Heart Attack Trial (ALLHAT): clinical center recruitment experience. Control Clin Trials 2001;22:659-73.

19. Marques-Vidal P, Bongard V, Ruidavels JB, et al. Effect of apolipoprotein $E$ alleles and angiotensin converting enzyme insertion/deletion polymorphisms on lipid and lipoprotein markers in middle aged men and in patients with stable angina pectoris or healed myocardial infarction. Am J Cardiol 2003;92:1102-5.

20. Danser AH, Schunkert H. Renin-angiotensin system gene polymorphisms: potential mechanisms for their association with cardiovascular diseases. Eur J Pharmacol 2000;410:303-16. 